\title{
A Cooperative Water Effect in Proazaphosphatrane-Catalysed Heterocycle Synthesis
}

\author{
Mark A. Honey, ${ }^{a}$ Yasuhiro Yamashita ${ }^{a, b}$ and Shu Kobayashi* ${ }^{b}$ \\ Received (in $X X X, X X X) X$ th $X X X X X X X X X 20 X X$, Accepted $X$ th $X X X X X X X X X 20 X X$ \\ ${ }_{5}$ DOI: $10.1039 / \mathbf{b 0 0 0 0 0 0 x}$
}

\begin{abstract}
The synthesis of oxazolines and imidazolines was achieved by activation of isocyanides with water. Mechanistic studies show that the organosuperbase proazaphosphatrane is tolerant of water within the reaction medium, with a 10 beneficial and cooperative effect being observed.
\end{abstract}

Catalytic carbon-carbon bond forming reactions are an immensely important set of reactions that help the synthetic organic chemist to construct important natural products and pharmacologically active molecules. ${ }^{1}$ Among these sets of 15 reactions are those in which base deprotonation of an acidic substrate is a key step in activating a pronucleophile towards nucleophilic addition. ${ }^{2}$ Such base-initiated reactions are often highly atom economical as no pre-functionalisation of substrates are required. Typically, strong organometallic bases such as metal 20 hydrides, ${ }^{3}$ metal amides ${ }^{4}$ and metal alkoxides ${ }^{5}$ are required to activate the pronucleophile, but as a result of their high basicity and high sensitivity towards moisture, the formation of undesired side-products or reduced activity due to water deprotonation is often observed. Although the use of organometallic bases have 25 become a staple for the organic chemist, organic bases such as DBU $^{6}{ }^{\text {pyridine }}{ }^{7}$ and imidazole ${ }^{8}$ among many others have also been employed in such systems, often producing a cleaner reaction profile as a result of their lower basicity. However, due to this decrease in basicity, their application is generally limited 30 to relatively activated substrates. Recently, a stronger class of organic base, the organosuperbase has emerged, having proven to be effective bases for a range of transformations. ${ }^{9}$ Among this class of organosuperbase, the phosphorus-containing proazaphosphatrane (PAP) has shown relatively broad utility as a 35 result of its high basisity compared to traditionally used organic bases $\left(\mathrm{pK}_{\mathrm{a}} \sim 33\right.$ in acetonitrile). ${ }^{10}$ However, as for many organometallic bases, one problem associated with the increased basicisty of PAPs are their generally regarded sensitivity towards water and alcohols, fearing deactivation of the base through 40 deprotonation. In order to truly exploit the benefits of using an organosuperbase such as PAP, a lack of sensitivity to water and tolerance of alcohols within substrates or additives would be truly advantageous.

With this in mind, we herein present a water-activated, PAP45 initiated selective synthesis of imidazolines and oxazolines from the weakly acidic benzyl isocyanide with imines and aldehydes respectively. To the best of our knowledge, this is the first example of a PAP containing system which is compatible in the presence of water. We also believe this to be a unique example so detailing water activation of isocyanides towards basedeprotonation.
The use of PAP with isocyanides has had little documented evidence, with its main use being to deprotonate the relatively activated ethyl 2-isocyanoacetate in the synthesis of oxazolines. ${ }^{11}$

${ }_{55}$ As only an activated isocyanide in combination with a high loading of PAP was used, we began to explore the ability of $i \mathrm{Bu}-$ PAP to initiate reactions involving less activated isocyanides. We chose benzyl isocyanide due to the large $\mathrm{pK}_{\mathrm{a}}$ difference between itself and the commonly used ethyl 2-isocyanoacetate, 60 and began investigating the synthesis of oxazolines from benzaldehyde.

Table 1 Water effect on oxazoline formation

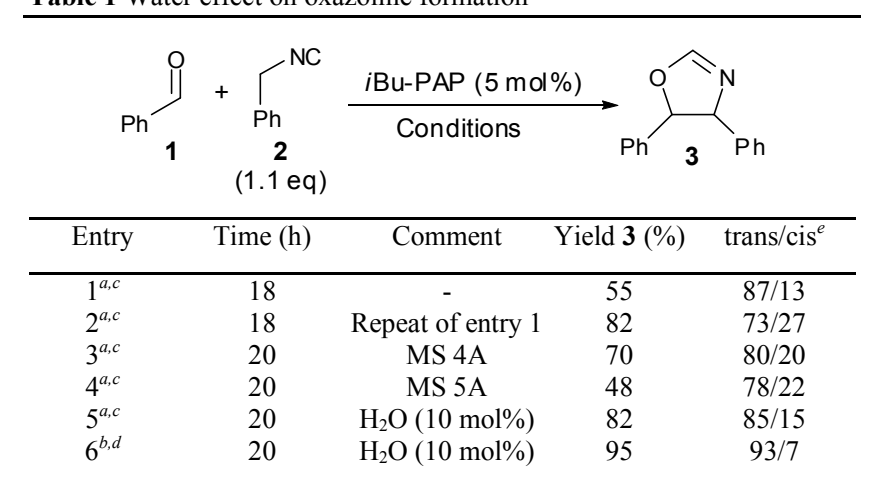

${ }^{a} \mathrm{DMF} /$ toluene (1/1) was used. ${ }^{b} \mathrm{DMF}$ was used. ${ }^{c} 75^{\circ} \mathrm{C} .{ }^{d} 100 \quad{ }^{\circ} \mathrm{C}$. ${ }^{e}$ determined by ${ }^{1} \mathrm{H}$ NMR analysis of the crude product

65 After an initial investigation of reaction conditions, the reaction combination in entry 1 , Table 1 gave the highest selectivity of the desired oxazoline 3. However, this experiment was not reproducible as every repeat reaction gave conflicting results. Although each reaction was performed under anhydrous 70 conditions, we speculated that the presence of a trace amount of water could rationalise these inconsistent findings. Therefore we added molecular sieves to remove any trace of water, but upon the addition of either MS 4A or MS 5A, a significant decrease in yield was observed along with the formation of uncharacterised 75 side-products. This was perplexing as $i \mathrm{Bu}-\mathrm{PAP}$ is known to be stable in the presence of dehydrating molecular sieves. ${ }^{12}$ As the removal of water had an apparent negative effect on our reaction system, we next investigated the addition of water. After some optimisation, we found that the presence of $10 \mathrm{~mol} \%$ water 80 actively stabilised our results, consistently giving our desired oxazoline in the same yield and selectivity. Although the above reaction proceeds smoothly at room temperature, higher temperatures are required in order to increase trans selectivity, presumably as the reaction changes from kinetic to 85 thermodynamic control. 
Encouraged by these initial findings, we next investigated the synthesis of imidazolines from benzyl isocyanide. In the case of imidazolines, the effect of water is rather more striking. Under stricktly anhydrous conditions, our desired reaction competely 5 failed to proceed. Remarkably, the addition of $10 \mathrm{~mol} \%$ water to the system gave our imidazoline in reasonable yield and good selectivity. Increasing the loading of water to $100 \mathrm{~mol} \%$ improved selectivity to $98 / 2$ and gave $\mathbf{5}$ in $80 \%$ yield. With the observation that water had a positive effect within our oxazoline 10 and imidazoline syntheses, its role within our reaction system was then examined.

Table 2 Water effect on imidazoline formation

\begin{tabular}{|c|c|c|c|c|}
\hline Entry & Solvent & Water Loading ${ }^{c}$ & Yield 5(\%) & $\operatorname{trans} / \operatorname{cis}^{d}$ \\
\hline $1^{a}$ & toluene & anhydrous & $\overline{\mathrm{NR}}$ & - \\
\hline $2^{b}$ & toluene & anhydrous & 26 & $55 / 45$ \\
\hline $3^{a}$ & THF & anhydrous & NR & - \\
\hline $4^{a}$ & THF & $10 \mathrm{~mol} \%$ & 47 & $94 / 6$ \\
\hline $5^{a}$ & THF & $20 \mathrm{~mol} \%$ & 76 & $96 / 4$ \\
\hline $6^{c}$ & THF & $100 \mathrm{~mol} \%$ & 80 & $98 / 2$ \\
\hline
\end{tabular}

${ }^{a} 25{ }^{\circ} \mathrm{C} .{ }^{b} 75{ }^{\circ} \mathrm{C} .{ }^{c} 40{ }^{\circ} \mathrm{C}$. ${ }^{d}$ determined by ${ }^{1} \mathrm{H}$ NMR analysis of the crude product

Proazaphosphatranes demonstrate an undeniably strongly basic nature, ${ }^{13}$ with Verkade previously noting that deprotonation of water by PAP is possible. ${ }^{14}$ Therefore, our first thought was $i \mathrm{Bu}-$ PAP hydroxide - the result of deprotonation of water by $i \mathrm{Bu}-\mathrm{PAP}$ 20 - was the actual base working within our system. However, after mixing $i$ Bu-PAP and water (up to 5 eq) in THF- $d_{8}$, DMF- $d_{7}$ or toluene- $d_{8}$, no deprotonation of water could be observed, even after a period of up to 18 hours. It is worth noting that upon addition of $i \mathrm{Bu}-\mathrm{PAP}$ to pure $\mathrm{D}_{2} \mathrm{O}$, deprotonation of $\mathrm{D}_{2} \mathrm{O}$ can be

25 instantly seen, presumably due to the increased acidity of $\mathrm{D}_{2} \mathrm{O}$ in its bulk form. 15

In light of the fact that our reaction with imines failed to proceed in the absence of water, and with the observation that $i \mathrm{Bu}-\mathrm{PAP}$ does not deprotonate water in our reaction system - and 30 therefore $i \mathrm{Bu}$-PAP hydroxide is not the active base - we next investigated the activation of imines by water via hydrogen bonding. Inspired by the report of Gschwind, ${ }^{16}$ we attempted to observe a change in the chemical shift of water due to hydrogen bonding with imine 4 by decreasing the sample temperature from $3525{ }^{\circ} \mathrm{C}$ to $-80{ }^{\circ} \mathrm{C}$ (see supporting information). Unfortunately only a very slight ${ }^{1} \mathrm{H}$ NMR chemical shift for water was observed, and although hydrogen bond activation of the imine probably does occur, we believe this effect to be slight. We also investigated the extent of hydrogen bonding between $i \mathrm{Bu}-\mathrm{PAP}$ and water, as the 40 lone pair on the phosphorus atom would be easily accessible. However, ${ }^{1} \mathrm{H}$ NMR experiments show little change in the chemical shift of water in the presence of $i \mathrm{Bu}-\mathrm{PAP}$, as well as little observable shifts in the corresponding ${ }^{31} \mathrm{P}$ NMR spectra, as might be expected if hydrogen bonding to phosphorus occurs. We 45 next turned our attention to benzyl isocyanide, as previous reports have shown that the isocyanide moiety readily complexes with hydrogen bond donors, ${ }^{17}$ with isocyanide activation via hydrogen bonding having already been utilised in organocatalytic reactions with thioureas. ${ }^{18}$ Comparison of the ${ }^{1} \mathrm{H}$ NMR spectra of water 50 and benzyl isocyanide and water in THF- $d_{8}$, shows a significant change in the chemical shift for water upon the addition of benzyl isocyanide. This chemical shift is most probably attributed to the interaction between the terminal isocyanide carbon and one or more molecules of water. Having observed substantial hydrogen 55 bonding between water and isocyanide, we finally investigated the effect of water on the deprotonation of benzyl isocyanide by $i \mathrm{Bu}-\mathrm{PAP}$, as hydrogen bond activation is known to increase acidity of the isocyanides $\alpha$-proton. ${ }^{19}$ When benzyl isocyanide was added to a solution of $i \mathrm{Bu}-\mathrm{PAP}$ in THF- $d_{8}$, it was clear to see 60 that only free $i \mathrm{Bu}-\mathrm{PAP}$ exists in solution, even after a period of 18 hours. However, with the addition of 1-15 equivalents of water, deprotonation of benzyl isocyanide was unmistakeably observed, with an indicative peak for $i \mathrm{Bu}-\mathrm{PAPH}+$ appearing at approximately $-8 \mathrm{ppm}$ in the ${ }^{31} \mathrm{P}$ NMR spectrum. Although this 65 communication mainly concentrates on the effect of water, isopropyl alcohol is also compatible with $i \mathrm{Bu}-\mathrm{PAP}$, which can act in a similar, albeit reduced manor, in facilitating deprotonation of benzyl isocyanide. As the reaction failed to proceed both in toluene and THF (Table 2) in the absence of water, we presume 70 that both non-polar and polar aprotic solvents have little effect on isocyanide activation.

Upon analysis of the combined experimental data just described, we conclude that the involvement of water in isocyanide activation is essential for deprotonation to occur. Although 75 hydrogen bonding undoubtedly exists between each component of our reaction system, and as such could play a pivotal role in stereochemical outcomes of applied reactions, our spectroscopic evidence clearly suggests that significant hydrogen bonding between the isocyanide moiety and water is the biggest 80 contributor, with a possible representation of the mode of activation being shown in Figure 1.

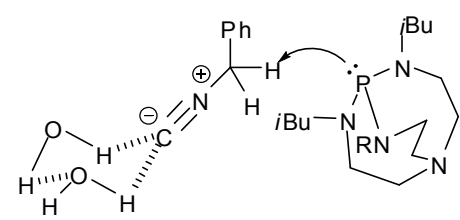

Figure 1 Isocyanide activation by water

With the above in mind, we propose the following 85 mechanism for both the imidazoline and oxazoline syntheses (Scheme 1). Firstly, the water activated isocyanide is deprotonated by $i \mathrm{Bu}-\mathrm{PAP}$, with $i \mathrm{Bu}-\mathrm{PAP}$ acting as a reaction initiator. The subsequently deprotonated isocyanide $7-$ which is possibly stabalised by hydrogen bonding with the phosphours90 bound hydrogen - attacks the electrophilic $\mathrm{sp}^{2}$ hybridised carbon of either an imine or aldehyde, giving the addition product 9 . Although the main role of water within this system is to activate the isocyanide, subtle electrostatic interactions between water and each reaction component is thought to influence the transition 95 state, and therefore the stereoselective outcome of this step. Subsequent cyclisation of the addition product 9 gives the desired heterocycle 10, which then acts as a product-base to deprotonate the next activated isocyanide. Although it is possible that the protonated $i \mathrm{Bu}-\mathrm{PAPH}+$ could act as a hydrogen bond donor to 100 activate the next equivalent of isocyanide, we believe this to be unlikely as the ionic interaction between the $i \mathrm{Bu}-\mathrm{PAPH}+$ cation and the anionic product to be relatively strong, with the subsequent orientation of $i \mathrm{Bu}-\mathrm{PAPH}+$ relative to the basic site of the heterocycle, due to steric hindrance associated with the now 105 puckered shape ${ }^{20}$ of $i \mathrm{Bu}-\mathrm{PAPH}+$ and the delocalisation of the cationic charge across the structure of $i \mathrm{Bu}-\mathrm{PAP}$, to disfavour this interaction.

Having elucidated the probable role of water within our reaction mixture, and with some previous optimisation 
experiments having been conducted, the substrate scope for both the reaction with aldehydes and imines was conducted.

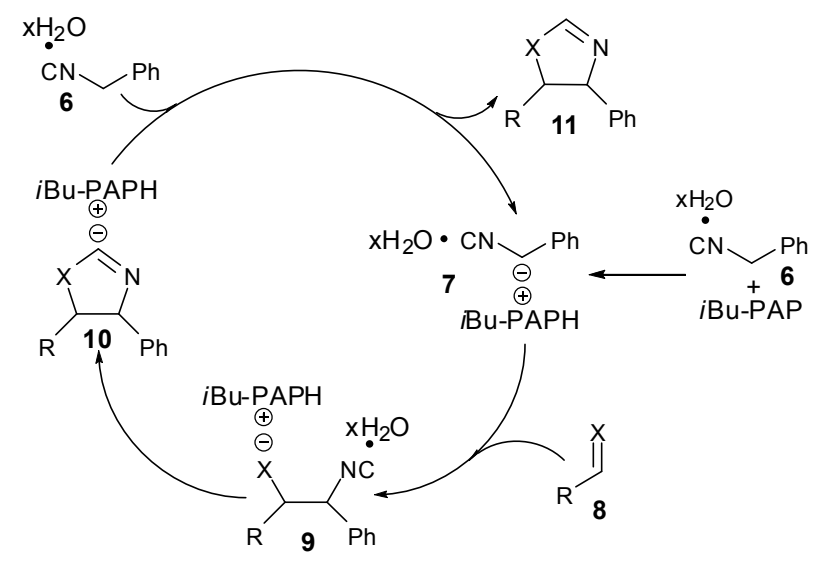

Scheme 1 Proposed mechanism

5 The entries in Table 3 demonstrate the applicability of numerous aldehydes and imines under our optimum reaction conditions. The reaction is tolerant of both aliphatic and aromatic substituents at $\mathrm{R}_{1}$, allows for variation around the aromatic ring, as well as accepting both electron donating and electron 10 withdrawing groups. Selectivities are excellent for the more sterically demanding substrates, although a more than satisfactory trans/cis ratio of 81/19 (entry 10) can be achieved with the use of the $n$-alkyl valeraldehyde.

Table 3 Oxazoline and imidazoline substrate scope

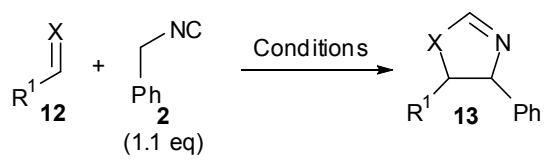

\begin{tabular}{|c|c|c|c|c|c|}
\hline$\overline{\text { Entry }}$ & $\mathrm{R}^{1}$ & $\mathrm{X}$ & Conditions & Yield $13(\%)^{b}$ & trans/ cis $^{c}$ \\
\hline 1 & $\overline{\mathrm{Ph}}$ & $\overline{\mathrm{O}}$ & $\overline{\mathrm{A}}$ & 95 & $93 / 7$ \\
\hline 2 & $4-\mathrm{OMeC}_{6} \mathrm{H}_{4}$ & $\mathrm{O}$ & A & 84 & $95 / 5$ \\
\hline 3 & $2-\mathrm{MeC}_{6} \mathrm{H}_{4}$ & $\mathrm{O}$ & A & 82 & $98 / 2$ \\
\hline 4 & $3-\mathrm{MeC}_{6} \mathrm{H}_{4}$ & $\mathrm{O}$ & A & 92 & $97 / 3$ \\
\hline 5 & 4- $-\mathrm{FC}_{6} \mathrm{H}_{4}$ & $\mathrm{O}$ & A & 73 & $89 / 11$ \\
\hline $6^{a}$ & 1-Napthyl & $\mathrm{O}$ & A & 86 & $78 / 22$ \\
\hline 7 & cyclohexyl & $\mathrm{O}$ & A & 80 & $94 / 6$ \\
\hline 8 & $t$ Butyl & $\mathrm{O}$ & A & 88 & $98 / 2$ \\
\hline 9 & $i$ Butyl & $\mathrm{O}$ & A & 82 & $83 / 17$ \\
\hline 10 & $n$ Butyl & $\mathrm{O}$ & A & 79 & $81 / 19$ \\
\hline $11^{d}$ & $\mathrm{Ph}$ & $\mathrm{O}$ & A & 76 & $88 / 12$ \\
\hline 12 & $\mathrm{Ph}$ & $\mathrm{NPh}$ & B & 80 & $98 / 2$ \\
\hline 13 & $\mathrm{Ph}$ & NPMP & B & 81 & $97 / 3$ \\
\hline 14 & 4- $-\mathrm{FC}_{6} \mathrm{H}_{4}$ & NPMP & B & 86 & $95 / 5$ \\
\hline 15 & $3-\mathrm{MeC}_{6} \mathrm{H}_{4}$ & NPMP & B & 54 & $98 / 2$ \\
\hline 16 & $2-\mathrm{BrC}_{6} \mathrm{H}_{4}$ & NPMP & B & 69 & $89 / 11$ \\
\hline $17^{e f, g, h}$ & cyclohexyl & NPMP & B & 43 & $91 / 9$ \\
\hline $18^{e, f g}$ & $n \mathrm{Bu}$ & NPMP & B & 70 & $77 / 33$ \\
\hline
\end{tabular}

15 Conditions A: $i$ Bu-PAP (5 mol\%), $\mathrm{H}_{2} \mathrm{O}(10 \mathrm{~mol} \%)$, DMF, $100{ }^{\circ} \mathrm{C}, 20 \mathrm{~h}$. Conditions B: $i$ Bu-PAP $(5 \mathrm{~mol} \%), \mathrm{H}_{2} \mathrm{O}(100 \mathrm{~mol} \%)$, THF, $40{ }^{\circ} \mathrm{C}, 24 \mathrm{~h}$. ${ }^{a}$ Reaction time was $56 \mathrm{~h}$. ${ }^{b}$ Isolated yield. ${ }^{c}$ Determined by ${ }^{1} \mathrm{H}$ NMR analysis of the crude product. ${ }^{d} i \mathrm{Bu}-\mathrm{PAP}(3 \mathrm{~mol} \%), \mathrm{H}_{2} \mathrm{O}(6 \mathrm{~mol} \%)$ was used. ${ }^{e}$ Imine formation with $\mathrm{MgSO}_{4}$ in DMF, filtration and addition of 20 crude product to the reaction mixture. ${ }^{f} \mathrm{DMF}$ was used. ${ }^{g}$ reaction was conducted at $100{ }^{\circ} \mathrm{C} .{ }^{h}$ Reaction time was $65 \mathrm{~h}$

In summary, we have described the first known example of a water tolerant $i \mathrm{Bu}-\mathrm{PAP}$ system, with mechanistic evidence
${ }_{25}$ eluding to the activation of isocyanide with water. We have utilised this cooperative water effect to increase the acidity of benzylic isocyanides for facile deprotonation by $i \mathrm{Bu}-\mathrm{PAP}$, for the subsequent synthesis of both oxazolines and imidazolines in good yield and selectivites.

30 This work was partially supported by a Grant-in-Aid for Science Research from the Japan Society for the Promotion of Science (JSPS), Global COE Program, The University of Tokyo, MEXT, Japan, and NEDO. M.A.H thanks the JSPS for the award of Postdoctoral Research Fellowship for Foreign Researchers and 35 for funding.

\section{Notes and references}

Department of Chemistry, School of Science, The University of Tokyo, Hongo, Bunkyo-ku, Tokyo 113-0033, Japan. E-mail: shu_kobayashi@chem.s.u-tokyo.ac.jp

$40 \dagger$ Electronic Supplementary Information (ESI) available: [details of any supplementary information available should be included here]. See DOI: $10.1039 / \mathrm{b} 000000 \mathrm{x} /$

1 (a) A. Joshi, J.-B. Veron, J. Unge, A. Rosenquist, H. Wallberg, B. Samuelsson, A. Hallberg and M. Larhed, J. Med. Chem., 2013, 56, 45 8999; (b); D. G. Stafford, O. Loe and H. M. L. Davies, Org. Lett., 2005, 7, 5561; (c) A. M. Jordan and S. D. Roughley, Drug Discovery Today, 2009, 14, 731

2 (a) T. D. Machajewski and C.-H. Wong, Angew. Chem. Int. Ed., 2000, 39, 1352; (b) J. M. M. Verkade, L. J. C. V. Hemert, P. J. L. M.

$50 \quad$ Quaedflieg and F. P. J. T. Rutjes, Chem. Soc. Rev., 2008, 37, 29; (c) M. Hatano, T. Horibe and K. Ishihara, J. Am. Chem. Soc., 2010, 132, 56

3 Y. Yamashita, H. Suzuki and S. Kobayashi, Org. Biomol. Chem., $2012, \mathbf{1 0}, 5750$

554 Y. Yamashita and S. Kobayashi, Chem. Eur. J., 2013, 19, 9420

5 N. Y. Turova, E. P. Turevskaya, V. G. Kessler and M. I. Yanovskaya, The Chemistry of Metal Alkoxides, Kluwer Academic Publishing, Massachusetts, 2002

6 R. Matsubara and S. Kobayashi, Chem. Eur. J., 2009, 15, 10684

607 T. Ishii, S. Fujioka, Y. Sekiguchi and H. Kotsuki, J. Am. Chem. Soc., 2004, 126, 9558

8 X.-G. Huang, J. Liu, J. Ren, T. Wang, W. Chen and B.-B. Zeng, Tetrahedron, 2011, 67, 6202

9 T. Ishikawa, Superbases for Organic Synthesis, John Wiley \& Sons 65 Ltd, Chichester, 2009

10 (a) P. B. Kisanga and J. G. Verkade, Aldrichimica ACTA, 2004, 37, 1; (b) P. B. Kisanga, J. G. Verkade and R. Schwesinger, J. Org., Chem., 2000, 65, 5431

11 P. Kisanga, P. Ilankumaran and J. G. Verkade, Tet. Lett., 2001, 42, 6263

12 J. Nakano, K. Masuda, Y. Yamashita, S. Kobayashi, Angew. Chem. Int. Ed., 2012, 51, 9525

13 P. B. Kisanga and J. G. Verkade, Tetrahedron, 2003, 59, 7819

14 A. E. Wroblewski, J. Pinkas and J. G. Verkade, Main Group Chem., $1995, \mathbf{1}, 69$

15 W. N. Olmstead, Z. Margolin and F. G. Bordwell, J. Org. Chem., 1980, 45, 3295

16 M. Fleischmann, D. Drettwan, E. Sugiono, M. Reuping and R. M. Gschwind, Angew. Chem. Int. Ed., 2011, 50, 6364

8017 P. V. R. Schleyer and A. Allerhand, J. Am. Chem. Soc., 1962, 84, 1322

18 H. Y. Kim and K. Oh, Org. Lett., 2011, 13, 1306

19 A. V. Gulevich, A. G. Zhdanko, R. V. A. Orru and V. G. Nenajdenko, Chem. Rev., 2010, 110, 5235

8520 J. G. Verkade, Coord. Chem. Rev., 1994, 137, 233 